\title{
Hypopharyngeal Cancer pN3 TNM Finding v8
}

National Cancer Institute

\section{Source}

National Cancer Institute. Hypopharyngeal Cancer pN3 TNM Finding v8. NCI Thesaurus. Code C132974.

Hypopharyngeal cancer with metastasis in a lymph node larger than $6 \mathrm{~cm}$ in greatest dimension and ENE(-); or metastasis in a single ipsilateral lymph node larger than $3 \mathrm{~cm}$ in greatest dimension and $\mathrm{ENE}(+)$; or metastases in multiple ipsilateral, contralateral, or bilateral lymph nodes any with ENE(+). (from AJCC 8th Ed.) 